\title{
Numerical model for mechanical behavior of lightweight concrete and for the prediction of local stress concentration
}

\author{
Etienne Malachanne ${ }^{\mathrm{a}, *}$, Rita Sassine $^{\mathrm{a}}$, Eric Garcia-Diaz ${ }^{\mathrm{a}}$, Frederic Dubois ${ }^{\mathrm{b}}$ \\ ${ }^{a}$ Centre des Materiaux des Mines d'Ales, Ecole des Mines d'Ales, Ales 30319, France \\ ${ }^{\mathrm{b}}$ Laboratoire de Mecanique et Genie Civil, UMR 5508, Universite Montpellier 2, cc048 Place Eugene Bataillon, Montpellier 34095, France
}

In this study a numerical approach to simulate elastic behavior of lightweight concrete, is presented, at mesoscopic level. Concrete is considered as a biphasic material, composed of a granular skeleton dis-persed in a mortar. Aggregates generation should respect a granular model where a maximum distance between aggregates is imposed. The granular media is also defined by a granular curve and a compacity. A numerical concrete sample is carried out, using three-dimensional finite element mesh. Here light-weight concretes are considered, where Young's modulus of natural sand based mortar is higher than the modulus of the lightweight coarse aggregates. Different concretes are carried out, according to exper-imental studies from literature, in order to distinguish the influence of Young's modulus contrast, and of the concrete compacity, on mechanical behavior. Then numerical compressive tests are realized until an experimental value of compressive strength, and the local stress and strain distribution around aggre-gates is studied, still remaining in the elastic domain. According to these results, breaking of this kind of concrete occurs when the maximum strain is reached in the lightweight aggregates surrounded mortar.

\section{Introduction}

At mesoscopic level, concrete could be described as a group of aggregates (inclusions) surrounded by a continued phase (matrix). In our model, this phase is considered as the mortar, and the inclusions are only the coarse aggregates. The elastic mechanical behavior of this composite depends both on material and structural properties:

- the elastic modulus for the inclusions and the matrix respectively,

- the volume fraction for both the inclusions and the matrix,

\footnotetext{
* Corresponding author. Tel.: +33466785686.

E-mail address: etienne.malachanne@mines-ales.com (E. Malachanne).
}

- the shape of inclusions,

- the granular distribution of the inclusions,

- the realistic location of the inclusions in the composite material.

The characterization of the elastic behavior of concrete, must be divided in two parts. First, the determination of a homogeneous elastic behavior is overall influenced by the two first parameter listed above. Several results have been carried out on this way, by analytical homogenization methods based on the representative volume element behavior and related to the hydrostatic forces as the Hashin and Shtrikman bounds [1], the two-sphere model proposed by Hashin [2] and the three-sphere model introduced by De Larrard [3] and Le Roy [4]. These models are less accurate when the contrast between the moduli of the inclusions and the matrix is important especially when the phenomenon of creep in the matrix 
leads to important drop of the modulus as shown in [5]. More sophisticated homogenization models based on the tensor of Eshelby [6] consider the shape of the particles (spheres for the Mori-Tanaka model $[7,8]$ or polygonal shapes for the auto coherent model [9]) and allow to apply any stress field on the VER. In a previous work [10], a homogeneous elastic modulus of concrete was determined by a numerical model and compared with the analytical homogenization model [7].

On the other hand, the estimation of local stress concentration around aggregates, needs to characterize accurately the elastic behavior. For that, the shape, the granular distribution and the location of inclusions must be taken into account. In this case, numerical approaches take the place of analytical ones. Numerical models, based on three-dimensional microstructures, obtained by microtomography, are among the more accurate for the representation of a realistic granular skeleton [5]. The classical finite element approaches, allow to describe a material with at most a thousand of inclusions. Indeed, the high number of finite elements needed for the discretization, tends to limit the number of aggregates represented in a concrete sample. Finally, concrete could be described as a granular skeleton based on coarse aggregates and embedded in a mortar compound by a cement paste and sand $[11,12]$. Aggregates are rather represented as spheres, dispersed randomly in the mortar [12-15]. In order to represent the mesostructure in a realistic way, a granular model could be adopted [16]. In this model, called the "De Larrard model", a thickness is imposed between coarse aggregates $[17,18]$.

The purpose of this paper, is to propose a numerical model which gives a characterization of the mechanical behavior of these lightweight concretes. This kind of mesoscopic description, is particularly well suited to concrete constituted by low rigid lightweight coarse aggregates, coated with a more rigid mortar based on natural sand. These families of lightweight concretes, are useful to reduce thermal bridge in the concrete structure [19]. Rupture mechanics on lightweight concrete, have provided various studies and interpretations in literature. Unlike traditional concretes, some studies observed compression rupture inside aggregates [20-23]. Others explained the rupture by the tensile stress concentration on the top of aggregates [24]. On the other hand, works of De Larrard [3], proposed a model with a perfect interface between mortar and aggregates, and supposed that the rupture was induced by compression inside mortar. An experimental study [25] showed that three ruptures modes, binded to the ratio between Young's modulus of aggregate and mortar, could be observed:

- tension rupture inside the bond aggregate/mortar for important ratios,

- compression rupture inside the mortar and the aggregates for intermediate ratios,

- compression rupture inside the aggregates for low ratios.

Experimental values of mechanical properties, provided by [2123 ], will be used on the following to calibrate the numerical model.

In a first time, a numerical generation of different concrete samples, will be carried out, taking into account the granular model of De Larrard [16]. Lightweight concrete samples, will be considered as bi-phasic material, with a perfect mechanical link between aggregates and mortar. In a second time, using a finite element software, numerical simulation will be realized, based on experimental data quoted previously, in order to visualize the repartition of the principal stresses and strains inside mortar and aggregates, and in a geometrical transition zone between aggregates and mortar, called transition zone in the following. An interpretation of the rupture mode will be proposed, from the numerical results.

\section{Material and methods}

\subsection{Generation of concrete}

Numerical generation of concrete, is carried out with an open platform called "LMGC90", developed at the University of Montpellier [26]. The numerical concrete sample generated, should respect both the granular model of "De Larrard" [16] and a granular curve imposed. Let us first briefly recall the main properties of the granular model.

\subsubsection{Granular model of "De Larrard"}

This model requires to respect a distance between two adjacent coarse aggregates, in order to save the granular skeleton from the segregation phenomenon and optimize the compacity. This distance, called the Maximum Mortar Thickness $(M M T)$, see Fig. 1, depends on the compacity of a sample, called $g$, and the virtual compacity, $g^{*}$. Compacity $g$ is the ratio between the volume of aggregates, $V_{\text {agg }}$, and the total volume of a sample, $V$, such as:

$g=\frac{V_{a g g}}{V}$

The virtual compacity is defined as the maximum density for a given mixture, and its expression for rounded aggregates, as lightweight aggregates, is defined in [16] as:

$g^{*}=1-0.47\left(\frac{d_{\min }}{d_{\max }}\right)^{0.22}$

where $d_{\min }$ and $d_{\max }$ are the minimum and maximum aggregates' diameter.

The distance MMT is depending on $g, g^{*}$ and $d_{\max }$ by the mathematical relationship:

$M M T=d_{\max }\left(\sqrt[3]{\frac{g^{*}}{g}}-1\right)$

\subsubsection{Generation of a granular curve}

As explained previously, the granular skeleton generated, needs to respect a granular curve, depending on the spreading and the shape of volume distribution. A method to generate this curve has been proposed by [27], based on the mathematical theory of distribution functions, and applied to granular media. A cumulative distribution function $\beta$ is used, defined by the Eq. (4):

$\beta\left(d_{r}, a, b\right)=\frac{1}{B(a, b)} \int_{0}^{d_{r}} t^{a-1}(-t)^{b-1} d t \quad$ with $\quad a>0, b>0$

where $a$ and $b$ are the parameters of the distribution allowing to control the shape of the granular curve. The variable $d_{r}$ is the reduced parameter, defined as follow:

$d_{r}=\frac{d-d_{\min }}{d_{\max }-d_{\min }}$

with $d$ the aggregate diameter. The function $B(a, b)$ is a weight function, according to distribution theory. The different shapes of the cumulative function $\beta$ are represented by Fig. 2 .

2.1.3. Generation of concrete at mesoscale level

The generation of concrete at mesoscale level, is now performed, according to

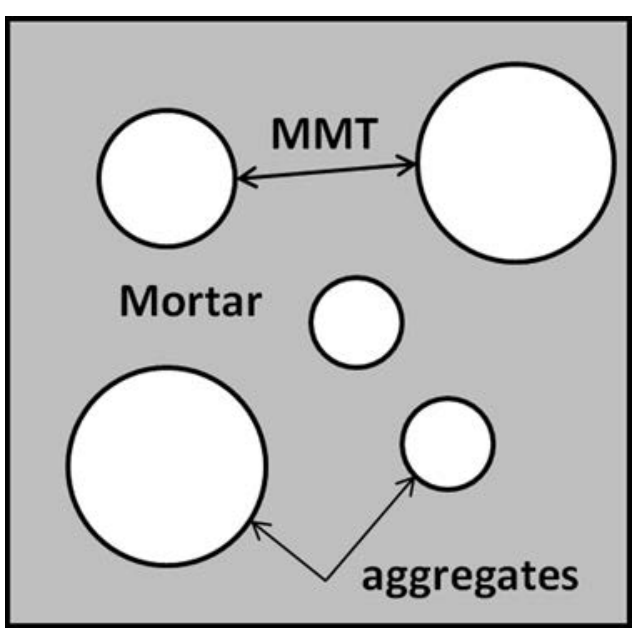

Fig. 1. Maximum mortar thickness between two aggregates. 


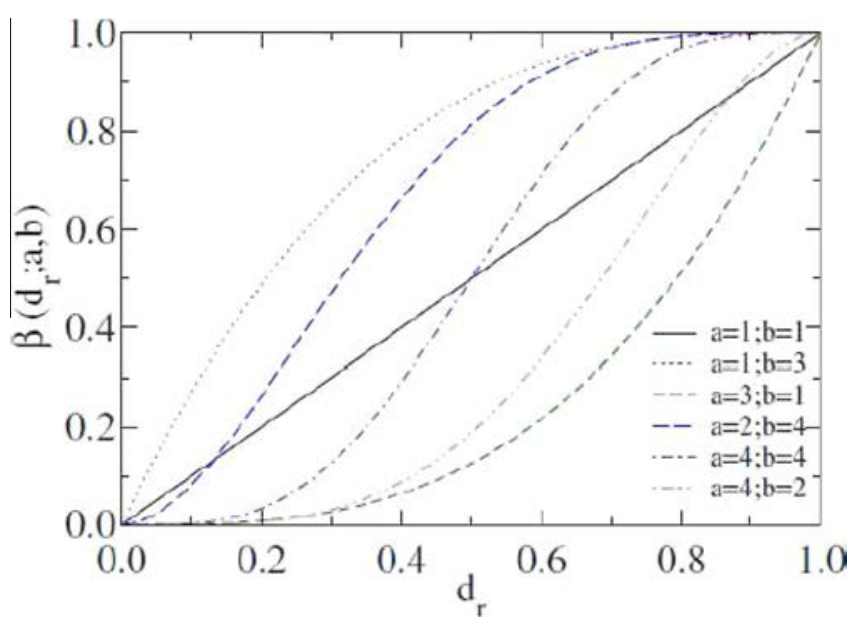

Fig. 2. Cumulative distribution curves for different values of a and b from [27].

the granular model of "De Larrard" and a specific granular curve. Main numerical steps are summarized by the following points:

- the location of aggregates is randomly chosen,

- the compacity and the aggregate's content of concrete sample is imposed,

- the aggregates, represented as spheres, are generated according to a granular curve,

- the MMT defined by (3) is taken into account during the aggregate generation.

\subsubsection{Spatial discretization of the concrete sample generated}

Once the concrete sample has been generated as detailed in the previous sections, a spatial discretization is needed. A finite elements meshing is chosen, using the three-dimensional mesh generator GMSH [28]. Mortar and aggregates are meshed separately, in order to take different sizes of tetrahedrons finite elements. The concrete generated takes into account a perfect mechanical link between aggregates and mortar, as consequence, the modelization of the interface between them is not required. The mesh carried out is shown by Fig. 3 .

\subsection{Experimental data from literature}

The numerical model presented here, proposes to study the mechanical behavior of lightweight concrete. In order to compare, and validate this model, experimental data are needed. Experimental works of [21-23], provides data on lightweight concretes, especially on elasticity parameters and compressive strengths. In concretes considered here, Young's modulus of mortar is higher than the modulus of aggregates. Two groups of aggregates are used, called $430 \mathrm{~A}$ and $750 \mathrm{~S}$, dispersed in the mortar with the compacities $g=12.5 \%$ and $g=45 \%$. These aggregates are embedded by two mortars, called by the authors M8 and M10.

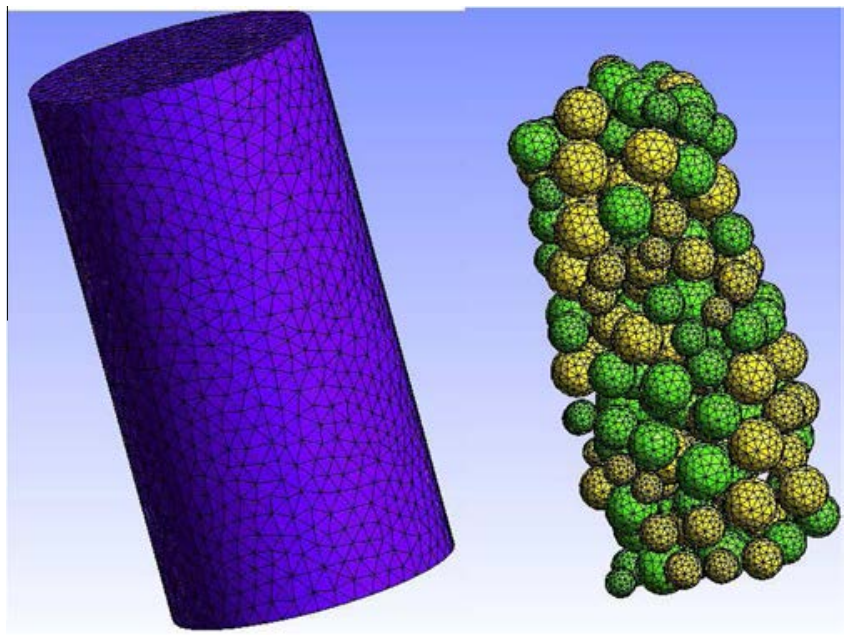

Fig. 3. Concrete meshed by finite elements with a compacity of $45 \%$.
Young's modulus of these two mortars have been determined experimentally by compression tests. Values of Young's modulus of lightweight aggregates, have been carried out using the phenomenological relationship (6) provided by [23,29]:

$E_{\text {agg }}=8000 \times \rho_{G}^{2}$

where $E_{a g g}$ is Young's modulus of lightweight aggregates and $\rho_{G}$ the density determined experimentally. Values of Young's modulus coming from this calculation have been validated with two methods [10]. Indeed, using a Mori-Tanaka homogenization method and a numerical model, an homogeneous Young's modulus of the concrete based on mortar M10 and lightweight aggregates 430A and 750S, has been calculated. In each case, values of Young's modulus coming from Eq. (6), allowed to identify the homogeneous Young's modulus obtained experimentally by [21].

Elastic parameters of the two materials composing the concretes, are summarized in Table 1, where $E$ is Young's modulus and $f_{c}$ the compressive strength. Finally, the numerical model has been validated on the concretes called M8-430A, M8750S, M10-430A and M10-750S, with the two compacities listed below.

Material parameters of the 8 concretes used in the numerical model, are shown on Table 2. The concretes realized with the more rigid mortar (M10) are stronger than the others. In the following Young's modulus of aggregates will be called $E_{a g g}$ and the compressive strength of mortar and concrete, repectively $f_{c m}$ and $f_{c}$.

\section{Calculation}

\subsection{Numerical simulation}

The finite element model of concrete presented in past sections is now used, to realize mechanical tests. All the simulations are carried out with the open platform LMGC90, used for modeling interacting objects with different shapes and mechanical behavior in two or three dimensions [26]. In a first time concrete is generated using geometrical, and material parameters presented previously. Then boundary conditions will be applied, in order to simulate a compression test, as close as experimental study.

Compacities of $12.5 \%$ and $45 \%$ are imposed, on concrete cylinders with a diameter of $40 \mathrm{~mm}$ and a height of $80 \mathrm{~mm}$. Granular curves of both concretes, calculated with the distribution theory, are shown on Fig. 4. One can notice that $d_{\max }=10 \mathrm{~mm}$ for both concretes. Thus the maximum aggregate diameter is four times higher than the diameter of the sample, which is enough to neglect boundary effects [30]. In Table 3 are recalled geometrical parameters of the granular skeleton, according to the "De Larrard" model.

Elastic parameters of the experimental concretes, presented in Table 2, are imposed, using the pre-processor of the software LMGC90. Then a compression loading is applied in each concrete, until the compressive strength $f_{c}$, determined experimentally and recalled in Table 2.

\section{Results}

Compression loadings applied on concrete samples, have given a mechanical elastic response. The validation of the numerical model has been realized in other studies [10], as noticed in previous section. In the following the principal stresses and strains, around aggregates will be studied.

\subsection{Principal stresses}

Concrete is an heterogeneous material and a compression loading cannot give a pure compression field in the material. For that, principal stresses are calculated, called $\sigma_{1}, \sigma_{2}, \sigma_{3}$, and $V_{1}, V_{2}, V_{3}$ are the principal axis associated. One can notice that

Table 1

Material parameters of mortar and aggregates from [23].

\begin{tabular}{llll}
\hline Material & Type & $E(\mathrm{GPa})$ & $f_{c m}(\mathrm{MPa})$ \\
\hline Mortar & M8 & 28 & 40 \\
Mortar & M10 & 35.4 & 86 \\
Aggregate & $430 \mathrm{~A}$ & 4.3 & \\
Aggregate & $750 \mathrm{~S}$ & 20 & \\
\hline
\end{tabular}


Table 2

Elastic material for concretes from [23].

\begin{tabular}{llll}
\hline Concrete & $g(\%)$ & $E(\mathrm{GPa})$ & $f_{c}(\mathrm{MPa})$ \\
\hline M8-430A & 12.5 & 25 & 37 \\
& 45 & 16 & 26 \\
M8-750S & 12.5 & 27 & 42 \\
& 45 & 24 & 43 \\
M10-430A & 12.5 & 30 & 63 \\
& 45 & 20 & 34 \\
M10-750S & 12.5 & 34 & 82 \\
& 45 & 33 & 73 \\
\hline
\end{tabular}

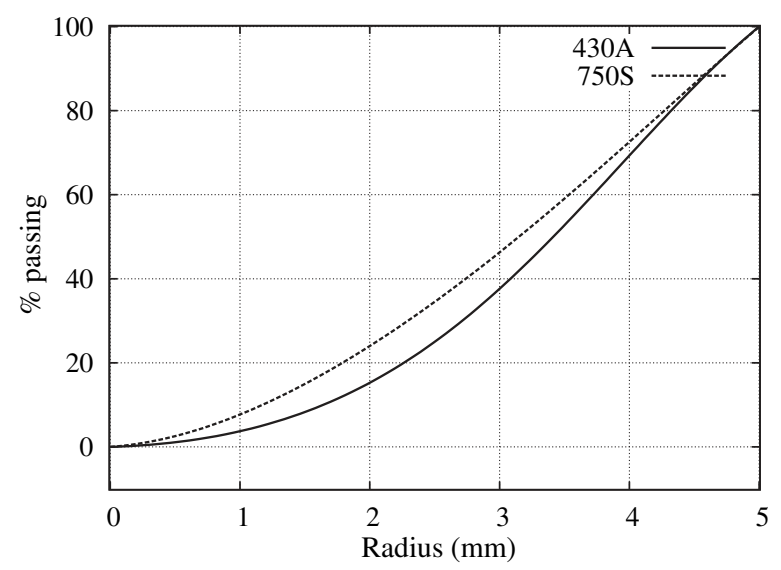

Fig. 4. Granular curves for the two kinds of lightweight concretes studied.

Table 3

Parameters of the granular skeleton calculated from the "De Larrard" model.

\begin{tabular}{lllll}
\hline$g(\%)$ & Aggregate & $d_{\min }(\mathrm{mm})$ & $g^{*}(\%)$ & $M M T(\mathrm{~mm})$ \\
\hline \multirow{2}{*}{12.5} & $430 \mathrm{~A}$ & 4 & 61.5 & 7 \\
& $750 \mathrm{~S}$ & 2 & 67 & 7.4 \\
\multirow{2}{*}{45} & $430 \mathrm{~A}$ & 4 & 61.5 & 1.1 \\
& $750 \mathrm{~S}$ & 2 & 67 & 1.4 \\
\hline
\end{tabular}

$V_{1}$ is quasi collinear with the compression axis, $(0, z)$. Principal stresses are calculated, on each node of the sample, but the results presented here are focused around aggregates.

The local stress evolution around an aggregate, is presented by Figs. 5 and 6 . The aggregate with the maximum diameter $\left(d_{\max }=10 \mathrm{~mm}\right)$ is chosen. Previously, some numerical tests have been made to study the influence of the size and the location of the aggregate chosen. It has appeared that these two parameters did not provide significant change on numerical results. Principal stresses values given here, have been selected on nodes along the axis $(0, x)$ and $(0, z)$, and passing by the aggregate center. It is important to mention that negative stresses indicate compression stresses while positive values are the tensile stresses. The stress $\sigma_{1}$ is higher than the two others and is always a compressive stress. On the other hand, $\sigma_{2}$ and $\sigma_{3}$ give sometimes tensile stresses. Aggregates and mortar zones are delimited, and as explained previously, a geometrical transition zone is defined, between mortar and aggregates, with a length included between $0.5 \mathrm{~mm}$ and $1.5 \mathrm{~mm}$. Maximum compression stress $\sigma_{1}$ is found along the $(0, x)$ axis, perpendicular to the loading axis. Moreover the maximum tensile values of $\sigma_{2}, \sigma_{3}$ are found along the $(0, z)$ axis. In the center of each aggregate, an uniform compressive stress is visualized. In this zone, $\sigma_{2}$ and $\sigma_{3}$ are approximately equal to zero. This uniform stress $\sigma_{1}$ is presented in Figs. 5 and 6 inside the gray circles. Highest tensile and compression stress values have been founded on concretes with mortar M10.

\subsection{Principal strains}

Principal strains are calculated using the Hooke's law for isotropic materials (7), $v$ being the Poisson's ratio, E Young's modulus, I the identity matrix, $\boldsymbol{\varepsilon}$ and $\boldsymbol{\sigma}$ are respectively the second order strain tensor, and stress tensor.

$\boldsymbol{\varepsilon}=-\frac{v}{E} \operatorname{Tr}(\boldsymbol{\sigma}) \mathbf{I}+\frac{1+v}{E} \boldsymbol{\sigma}$

The evolution of the principal strain $\varepsilon_{1}$, around an aggregate and along the $(0, x)$ axis is represented in Fig. 7 and Fig. 8. One can notice that strain distribution is not symmetric about the axis passing by the center of the inclusion. It can be due to the location of the

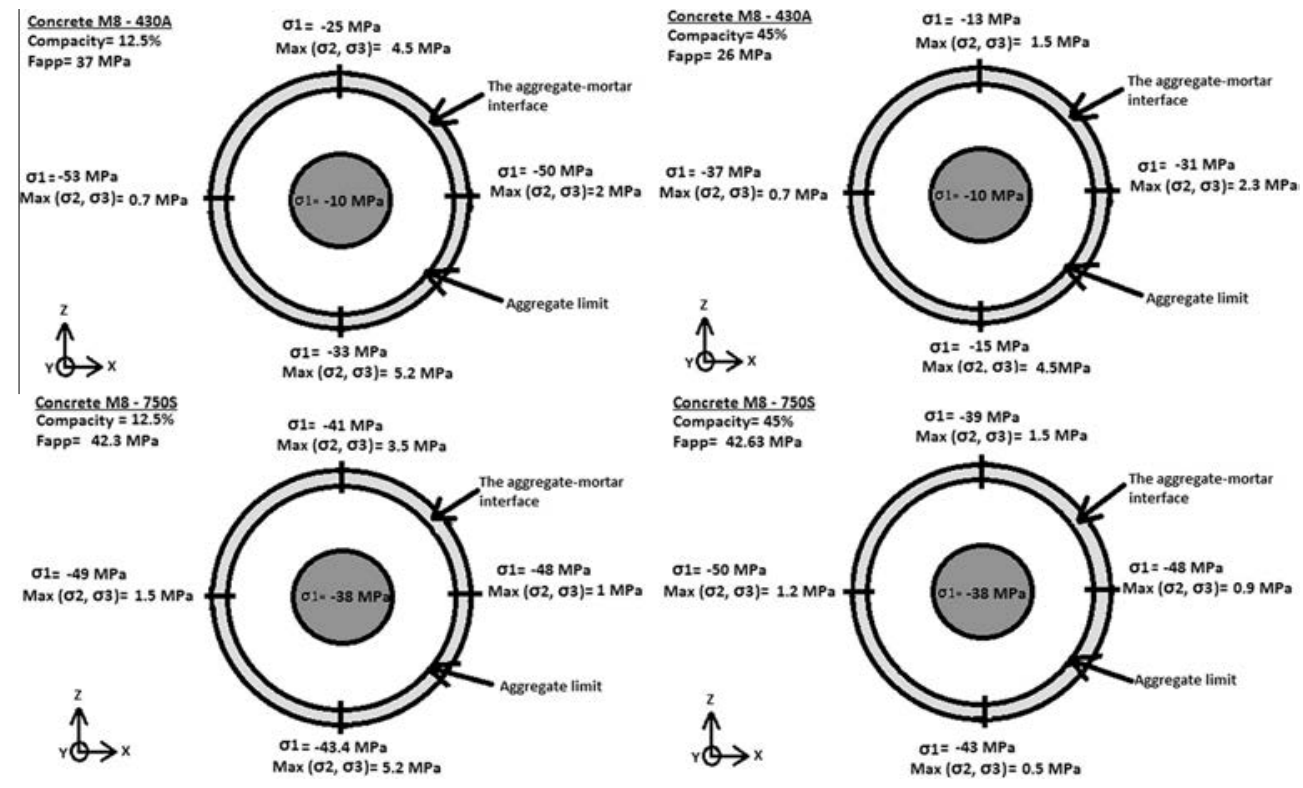

Fig. 5. Principal stresses evolution around an aggregate for concrete M8. 


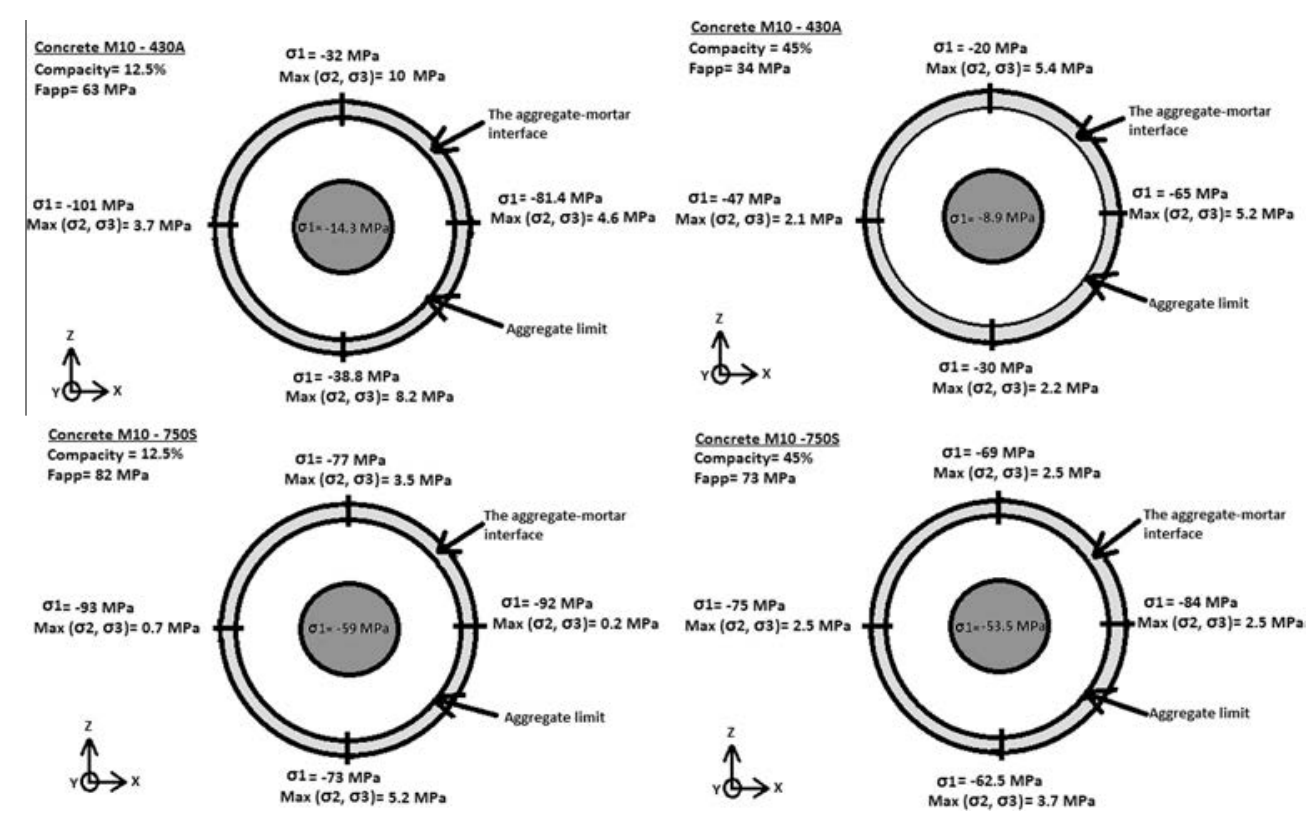

Fig. 6. Principal stresses evolution around an aggregate for concrete M10.

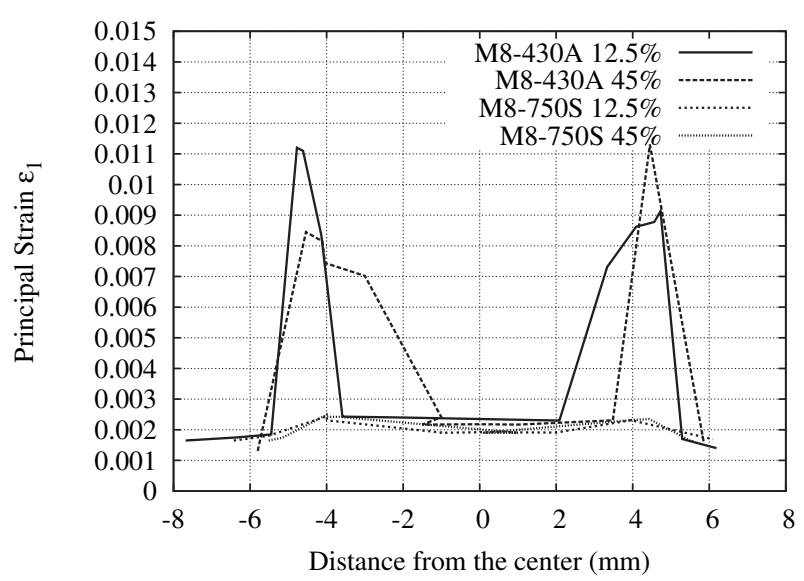

Fig. 7. Evolution of the principal strain $\varepsilon_{1}$ around an aggregate for concrete with mortar M8.

selected grain, or to the neighboring aggregates. Moreover, principal stresses and strains are calculated on nodes, and their position can influence the results.

\section{Discussion}

Numerical results have given internal stress and strain fields, for lightweight concretes with a perfect mechanical link between mortar and aggregates, loaded at the compressive strength value. In this section, we focused on stress and strain distribution in mortar and aggregates, and we will try to link them with possible failure modes. A comparison with numerical results and a rheological model for predicting the compressive strength of lightweight concrete, proposed by De Larrard [3,16], will be presented in order to justify a sole and unique failure mode, shared by every concretes studied here.

\subsection{Uniform state on compression inside aggregates}

The compression rupture inside aggregates has been proposed by some studies, as cited previously [3]. Figs. 5 and 6 show an uniform compressive stress aggregate core. These values depend on mortar and aggregate types, and present a convergence. Nevertheless values of compressive stress inside aggregates are higher for concrete with mortar M10, than for the ones with mortar M8. For example, in the center of aggregates $750 \mathrm{~S}$, compressive stress equals to $38 \mathrm{MPa}$ for concrete with mortar M8 and around $55 \mathrm{MPa}$ for concrete with mortar M10. Assuming that $55 \mathrm{MPa}$ be the compressive strength of aggregate $750 \mathrm{~S}$ for concrete with mortar M10, it means that for concrete with mortar M8 the compressive strength would be $38 \mathrm{MPa}$, for the same aggregate. It would be an inconsistency result. This tendancy is noticeable for both concretes. Moreover, the lack of knowledge in experimental compressive strength of lightweight aggregates, does not allow to conclude on the failure of concrete inside aggregates.

\subsection{Rupture when maximum admissible strain is reached in mortar}

On Figs. 7 and 8, one can notice that, in the mortar, away from the geometrical transition zone, strains converge. Let us study accurately this phenomenon, and compare them with the maximum admissible strain determined experimentally by [22]. Since the mechanical behavior in mortar is purely compressive, the admissible total strain before the rupture can be approximated as:

$\varepsilon_{\max }=\frac{f_{c m}}{E_{m}}$

where $f_{c m}$ is the compressive strength for mortar and $E_{m}$ Young's modulus, and assuming that the mechanical behavior is quasi-elastic until the compressive strength. Using experimental data of mortars, Eq. (8) gives a maximum strain such as $\varepsilon_{\max }=1.45 \times 10^{-3}$ for mortar M8 and $\varepsilon_{\max }=2.45 \times 10^{-3}$ for mortar M10. All values are summarized in Table 4. For each value, the location where the strain has been performed is indicated, $d_{c}$ representing the distance from the center of aggregate. A correlation is observed between numerical strain calculated inside the mortar, far from the aggregate center, and the experimental maximum strain. The difference between numerical and experimental values, is included between $0.8 \%$ and $13.8 \%$ for concrete with mortar M10 and between 3.4\% and $16.5 \%$ for the one with mortar M8. On can notice that for a loading until the compressive strength of concrete, the maximum admissible strain is reached on mortar, for every concretes tested 


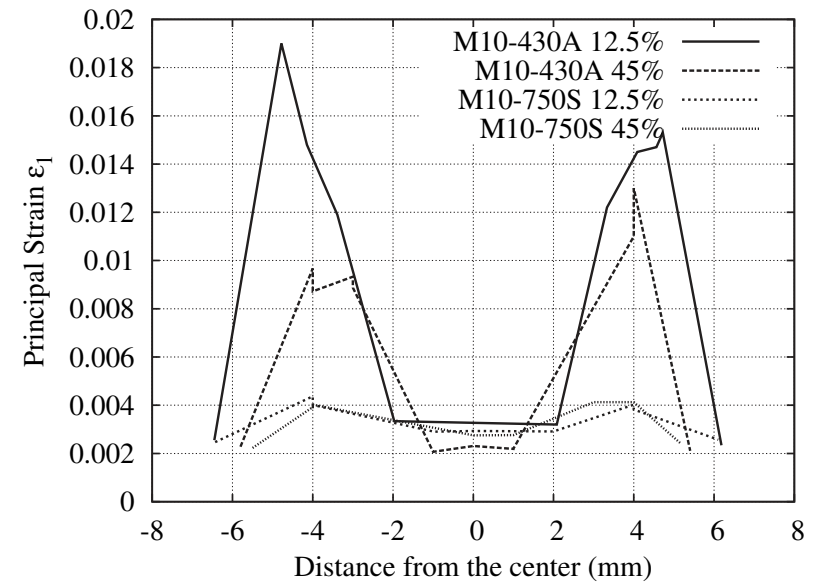

Fig. 8. Evolution of the principal strain $\varepsilon_{1}$ around an aggregate for concrete with mortar M10.

here. Thus it is allowed to consider that the concrete compressive strength is only induced by the failure of mortar.

In order to determine the influence of the error in numerical strain calculated, it is interesting to use the numerical model as a prediction tool for concrete compressive strength. Indeed if the failure in concrete is induced by the mortar, then the numerical simulation performed until the maximum admissible strain, would give a stress imposed around the compressive strength. For that, boundary conditions of the numerical concrete sample are modified, in order to apply in mortar a strain about $1.45 \times 10^{-3}$ in concrete with mortar M8 and $2.45 \times 10^{-3}$ in concrete with mortar M10. When this strain is reached on points located in Table 4, numerical computation is stopped and stresses in lower and upper faces of numerical concrete samples are picked up and compared with the experimental compressive strength. In Table 5 the average of stresses calculated on either side of aggregates, is compared with experimental values of compressive strength. One can notice that the numerical models gives a quite accurate prediction.

A linear regression is performed between experimental and numerical results, see Fig. 9. The slope of the line equals 1.01 and the regression coefficient is about $R^{2}=0.98$. Thus, the

Table 4

Strain values inside both concrete with mortar M8 and M10.

\begin{tabular}{lrlll}
\hline Concrete type & $d_{c}(\mathrm{~mm})$ & $\varepsilon_{\text {num }}$ & $\varepsilon_{\text {exp }}$ & Error $(\%)$ \\
\hline M8-430A 12.5\% & -7.6 & $1.65 \times 10^{-3}$ & $1.45 \times 10^{-3}$ & 13.8 \\
& 6.18 & $1.40 \times 10^{-3}$ & $1.45 \times 10^{-3}$ & -3.4 \\
M8-430A 45\% & -5.8 & $1.31 \times 10^{-3}$ & $1.45 \times 10^{-3}$ & -9.6 \\
& 5.9 & $1.56 \times 10^{-3}$ & $1.45 \times 10^{-3}$ & 7.6 \\
M8-750S 12.5\% & -6.43 & $1.65 \times 10^{-3}$ & $1.45 \times 10^{-3}$ & 13.8 \\
& 6.1 & $1.69 \times 10^{-3}$ & $1.45 \times 10^{-3}$ & 16.5 \\
M8-750S 45\% & -5.5 & $1.65 \times 10^{-3}$ & $1.45 \times 10^{-3}$ & 13.8 \\
& 5.41 & $1.61 \times 10^{-3}$ & $1.45 \times 10^{-3}$ & 11 \\
M10-430A 12.5\% & -6.45 & $2.55 \times 10^{-3}$ & $2.45 \times 10^{-3}$ & 4 \\
M10-430A 45\% & 6.18 & $2.34 \times 10^{-3}$ & $2.45 \times 10^{-3}$ & -4.7 \\
& -5.8 & $2.28 \times 10^{-3}$ & $2.45 \times 10^{-3}$ & -6.9 \\
M10-750S 12.5\% & 5.41 & $2.11 \times 10^{-3}$ & $2.45 \times 10^{-3}$ & -13.8 \\
& -6.43 & $2.47 \times 10^{-3}$ & $2.45 \times 10^{-3}$ & 0.8 \\
M10-750S 45\% & 6.1 & $2.57 \times 10^{-3}$ & $2.45 \times 10^{-3}$ & 4.9 \\
& -5.5 & $2.23 \times 10^{-3}$ & $2.45 \times 10^{-3}$ & -8.9 \\
& 5.41 & $2.43 \times 10^{-3}$ & $2.45 \times 10^{-3}$ & -0.8 \\
\hline
\end{tabular}

numerical simulation, remaining in the elastic domain, and assuming that the failure occurs in mortar, allows to predict the compressive strength of the lightweight concrete studied here.

Let us now compare this result, with the rheological model parallel/series proposed by De Larrard in [16]. This rheological model is used to predict the compressive strength of lightweight concrete. As in the numerical model proposed here, the failure of concrete is supposed governed by the part of the mortar in parallel. The simplest rheological model used for the prediction of compressive strength, is presented by De Larrard as shown in Fig. 10. In this model, where the aggregates are assumed to be cubic, aggregates are called LWA for lightweight aggregates, and their compacity equals to $g$. It is an uniaxial parallel/series model, with a compacity of mortar about $1-g$, decomposed as: $1-g=1-g^{1 / 3}+g^{1 / 3}-g$.

According to this model, the relationship between the compressive strength of mortar $f_{c m}$, and the compressive strength of concrete $f_{c}$ is:

$$
f_{c m}=f_{c} \frac{E_{m}}{\left(1-g^{2 / 3}\right) E_{m}+g^{2 / 3} E_{g}}
$$

where $E_{m}$ is Young's modulus of mortar and $E_{g}$ Young's modulus of aggregates. Compressive strength of concrete can be deduced from (9) as follows:

$f_{c}=\left[1-\left(1-\frac{E_{g}}{E_{m}}\right) g^{2 / 3}\right] f_{c m}$

Using (10) values of predicted compressive strength of concrete are provided in Table 6 and called $f_{c s p}$

In order to compare these values with experimental values, a linear regression has been made and presented in Fig. 11. One can notice a good prediction of the concrete compressive strength, however less accurate than numerical model. Indeed, the slope of the linear regression equals 0.94 versus 1.01 for the numerical model. In the same way, the calculation of the correlation coefficient, has given $R^{2}=0.94$ which is lower than $R^{2}$ calculated before. Thus the numerical and rheological model presented, have shown a maximum strain reached in mortar when the concrete is loaded at the compressive strength. Then for the lightweight concrete studied here, the failure seems to be drived by the mortar.

\subsection{Stress concentrations in the geometrical transition zone}

In the geometrical transition zone defined previously, one can notice an increase of compressive stresses, moreover for concretes with the highest ratio between Young's modulus of mortar and aggregates. Indeed values of compressive stresses, given by numerical simulation, can reach until $100 \mathrm{MPa}$ for concrete M10-430 for a compacity of $12.5 \%$, as shown by Fig. 6 . These phenomena are also visible with strains. In Figs. 7 and 8, peaks of strains are observables in the geometrical transition zone, even more for aggregates 430A, with the lowest Young's modulus. As explained previously, in these concretes, a cracking inside mortar is proposed. These peak of strains, and stresses, probably show the limits of an elastic modelization of concretes. Indeed in this modelization, no damage effects have been taking into account. Since a damage evolution occurs, it stays confined and does not impact breaking in the mortar. If the rupture occured in this transition zone, it would be impossible to reach the maximum admissible strain in the mortar. Moreover this hypothesis is suggested by works of [31,3], where the mechanical modelization of the interface is not always needed for compressive strength prediction. 
Table 5

Comparisons between compressive strength predicted with numerical model and experimental results.

\begin{tabular}{llll}
\hline Concrete type & $f_{c}(\mathrm{MPa})$ & $f_{\text {cnum }}(\mathrm{MPa})$ & Error $(\%)$ \\
\hline M10-430A 12.5\% & 63 & 60.5 & 3.9 \\
M10-430A 45\% & 63 & 66 & -4.7 \\
M10-750S 12.5\% & 34 & 36.5 & -7.4 \\
& 34 & 39.4 & -16.1 \\
M10-750S 45\% & 82 & 81.3 & 0.8 \\
& 82 & 78.2 & 4.6 \\
M8-430A 12.5\% & 73 & 80.2 & -9.8 \\
M8-430A 45\% & 73 & 73.6 & -0.8 \\
M8-750S 12.5\% & 37 & 32.5 & 12.1 \\
& 26 & 38.3 & -3.6 \\
M8-750S 45\% & 26 & 28.7 & -10.6 \\
& 42.3 & 24.1 & 7 \\
& 42.3 & 37.1 & 12.1 \\
& 42.3 & 36.3 & 14.2 \\
& 42.3 & 37.5 & 12.1 \\
\end{tabular}

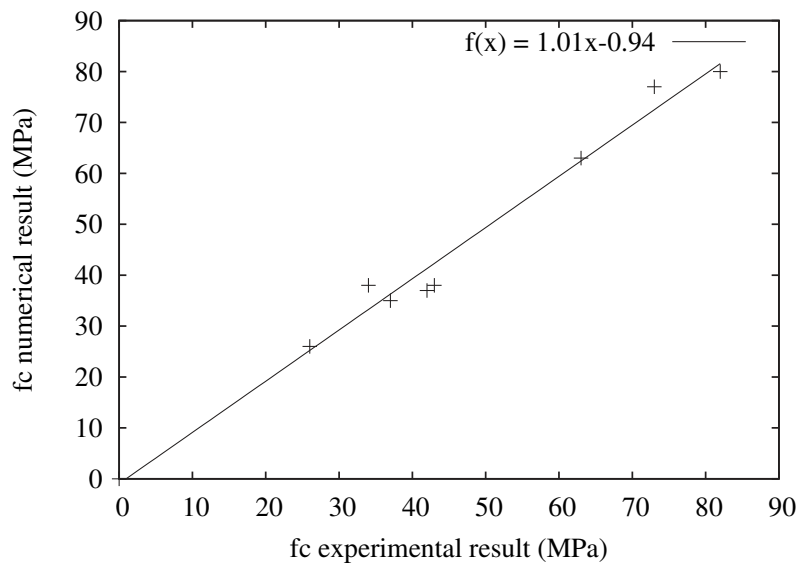

Fig. 9. Correlation between $f_{c}$ and $f_{\text {cnum }}$.

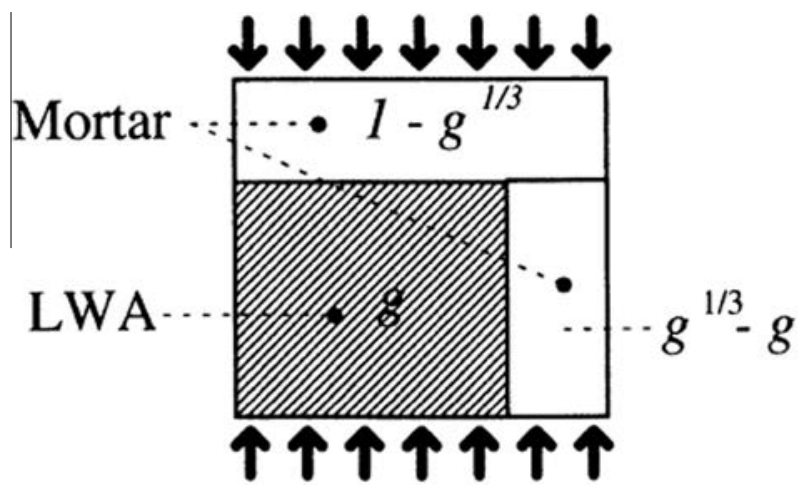

Fig. 10. Rheological model for the prediction of compressive strength in lightweight concrete from [16].

\section{Conclusion}

This work proposes a numerical model for lightweight concrete, with a three-dimensional modelization of the granular skeleton,
Table 6

Compressive strength of concrete predicted by the uniaxial parallel/series model.

\begin{tabular}{ll}
\hline Concrete type & $f_{\text {csp }}$ (MPa) \\
\hline M10-430A 12.5\% & 67 \\
M10-430A 45\% & 42 \\
M10-750S 12.5\% & 77 \\
M10-750S 45\% & 64 \\
M8-430A 12.5\% & 32 \\
M8-430A 45\% & 20 \\
M8-750S 12.5\% & 37 \\
M8-750S 45\% & 33 \\
\hline
\end{tabular}

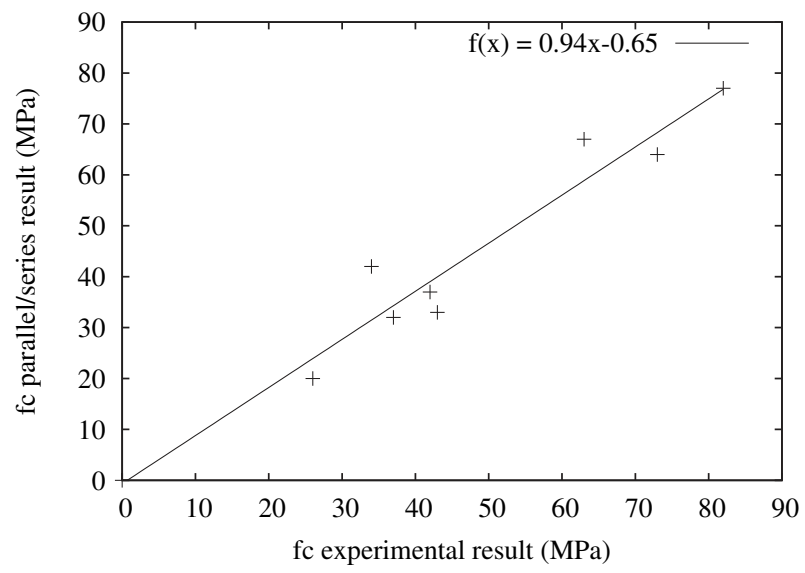

Fig. 11. Correlation between $f_{c}$ and $f_{c s p}$.

following the "De Larrard" granular model. All the tests have been based on experimental works, studying concrete with different ratios between Young's modulus of mortar and aggregates. Concretes have been modelized as a bi-phasic material, only composed of mortar and aggregates, with a perfect mechanical link between them. The visualization of local strain distribution, for an elastic mechanical behavior, has shown that a phenomenon of strain concentration exists in the geometrical transition zone defined, and it increases with the ratio between Young's modulus of mortar and aggregates. Nevertheless, the maximum strain is reached in mortar, out of the transition zone, when the experimental compressive strength value is applied. This means that, for the concrete studied here, the compressive strength of concrete is only binded to the compressive strength of mortar, and it is possible to predict the compressive strength of concrete, knowing the maximum admissible strain of mortar, still remaining in elastic domain. Other studies, on different concretes, have to be realized in order to improve this result. Moreover, a modelization of the mechanical behavior of the interface between aggregates and mortar is needed, with for example a cohesive zone model [32-34], in order to take into account damage effects in the stress concentration zone.

\section{References}

[1] Hashin Z, Shtrikman S. A variational approach to the theory of the elastic behaviour of multiphase materials. J Mech Phys Solids 1963;11:127-40.

[2] Hashin Z. The elastic moduli of heterogeneous materials. J Appl Mech 1962:29:143-50.

[3] De Larrard F. Mixture proportioning of lightweight aggregate concrete. In: International conference on high-performance concrete and performance and quality of concrete structures; 1996. p. 154-66.

[4] Le Roy R. Deformations instantanees et differees des betons e hautes performances. PhD thesis. Ecole Nationale des Ponts et Chaussees (France); 1995. 
[5] Escoda J, Willot F, Jeulin D, Sanahuja J, Toulemonde C. Estimation of local stresses and elastic properties of a mortar sample by fft computation of fields on a 3d image. Cement Concr Res 2011;41:542-56.

[6] Eshelby JD. The determination of the elastic field on an ellipsoidal inclusion, and related problems. In: Royal society; 1957.

[7] Mori T, Tanaka K. Average stress in matrix and average elastic energy of materials with misfitting inclusions. Acta Metall Mater 1973;21:571-4.

[8] Benveniste Y. A new approach to the application of mori-tanaka's theory in composite materials. Mech Mater 1987;6:147-57.

[9] Hill R. A self-consistent mechanics of composite materials. J Mech Phys Solids 1965;13:213-22.

[10] Sassine R, Malachanne E, Garcia-Diaz E, Dubois F, Vinches M. Numerica simulation prediction for the elastic behavior of concrete taking into account its mesoscopic structure. In: European congress on computational methods in applied sciences and engineering, ECCOMAS 2012; 2012. p. 154-66.

[11] Caballero A, Lopez CM, Carol I. 3d meso-structural analysis of concrete specimens under uniaxial tension. Comput Methods Appl Mech Eng 2006;195:7182-95.

[12] Wang Z, Kwan A, Chan H. Mesoscopic study of concrete i: generation of random aggregate structure and finite element mesh. Comput Struct 1999;70:533-44.

[13] Leite JPB, Slowik V, Apel J. Computational model of mesoscopic structure of concrete for simulation of fracture processes. Comput Struct 2007;85:1293-303.

[14] N'Guyen D, Lawrence C, La Borderie C Matallah M, Nahas G. A mesoscopic model for a better understanding of the transition from diffuse damage to localized damage. Euro J Environ Civil Eng 2010;14:751-76.

[15] Shahbeyk S, Hosseini M, Yaghoobi M. Mesoscale finite element prediction of concrete failure. Comput Mater Sci 2011;50:1973-90.

[16] De Larrard F. Concrete mixture proportioning. London and New York: E\&FN Spon; 1999.

[17] Comby-Peyrot I, Bouchard P-O, Bay F, Bernard F, Garcia-Diaz E. Numerica aspects of a problem with damage to simulate mechanical behavior of a quasibrittle material. Int J Comput Mater Sci Surface Eng 2007;40:327-40.

[18] Comby-Peyrot I, Bernard F, Bouchard P-O, Bay F, Garcia-Diaz E. Developmen and validation of a $3 \mathrm{~d}$ computational tool to describe concrete behaviour at mesoscale. application to the alkali-silica reaction. Comput Mater Sci 2009;46:1163-77.
[19] Clarke JL. Structural lightweight aggregate concrete. Blackie Academic and Professional; 1993.

[20] Wilson HS, Malhotra VM. Development of high strength lightweight concrete for structural applications. Int J Cement Compos Lightweight Concr 1988:10:79-90.

[21] Ke Y. Caracterisation du comportement mecanique des betons de granulats legers: experience et modelisation. PhD thesis. University of Cergy-Pontoise (France); 2008

[22] Ke Y, Beaucour AL, Ortola S, Dumontet H, Cabrillac R. Influence of volume fraction and characteristics of lightweight aggregates on the mechanical properties of concrete. Construct Build Mater 2009;23:2821-8.

[23] Ke Y, Ortola S, Beaucour AL, Dumontet $\mathrm{H}$. Identification of microstructural characteristics in lightweight aggregate concretes by micromechanical modelling including the interfacial transition zone (itz). Cement Concr Res 2010;40:1590-600.

[24] Bremner TW. In fluence of aggregate structure on low density concrete. PhD thesis. Imperial college of science and technology. London; 1981.

[25] Shink M. Compatibilite elastique, comportement mecanique et optimisation des betons de granulats legers. PhD thesis. University of Laval, Quebec; 2003.

[26] Dubois F, Jean M, Renouf M, Mozul R, Martin A, Bagneris M. Lmgc90. In: Colloque national en calcul des structures, CSMA; 2011.

[27] Voivret C, Radjaï F, Delenne J-Y, El Youssoufi MS. Space-filling properties of polydisperse granular media. Phys Rev E 2007;76:021301.

[28] Geuzaine C, Remacle J-F. Gmsh: a three-dimensional finite element mesh generator with built-in pre- and post-processing facilities. Int J Numer Methods Eng 2009;79:1309-31.

[29] A.C. 213, ACI 213R-03 Guide for Structural Lightweight-Aggregate Concrete. American Concrete Institute; 2003.

[30] Reynouard JM, Pijaudier-Cabot G. Comportement mecanique du beton. Lavoisier; 2005.

[31] Yang C, Huang R. A two-phase model for predicting the compressive strength of concrete. Cement Concr Res 1996;26:1567-77.

[32] Elices M, Rocco C, Rosello C. Cohesive crack modelling of a simple concrete: experimental and numerical results. Eng Fract Mech 2009;76:1398-410.

[33] Raous M, Cangemi L, Cocu M. A consistent model coupling adhesion, friction, and unilateral contact. Comput Methods Appl Mech Eng 1999;177:383-99.

[34] Perales F, Bourgeois S, Chrysochoos A, Monerie Y. Two field multibody method for periodic homogenization in fracture mechanics of nonlinear heterogeneous materials. Eng Fract Mech 2008;75:3378-98. 